University of Minnesota Morris Digital Well

University of Minnesota Morris Digital Well

$12-10-2018$

\title{
Are You Ready for Your Close-Up? Creating a Library Promotional Video
}

Peter Bremer

University of Minnesota - Morris, pbremer@morris.umn.edu

Follow this and additional works at: https://digitalcommons.morris.umn.edu/library

Part of the Library and Information Science Commons

\section{Recommended Citation}

Bremer, Peter. "Are You Ready for Your Close-Up? Creating a Library Promotional Video." The Reference Librarian, 2010.

This Article is brought to you for free and open access by the Faculty and Staff Scholarship at University of Minnesota Morris Digital Well. It has been accepted for inclusion in Library Publications by an authorized administrator of University of Minnesota Morris Digital Well. For more information, please contact skulann@morris.umn.edu. 


\section{Are You Ready For Your Close-Up? Creating a Library Promotional Video Peter Bremer \\ The Reference Librarian \\ Published online: 10 Dec 2018 \\ https://doi.org/10.1080/02763877.2018.1554518}

Librarians have a lot of competition when it comes to helping students. Classmates and search engines can be attractive options, especially for those with a reluctance in asking for help. Inexperienced researchers may not even realize what the library can do for them. As head of reference desk services at the Rodney A. Briggs Library it's my job to make sure that students and faculty are aware of what services we have to offer. This includes research and information assistance, technology troubleshooting and finding materials. Our community of users can interact with us face-to-face at the reference desk as well as through chat, text, voice and email.

Based on Gimlet report statistics of reference desk traffic it is clear that a majority (almost 90\%) of our users approach us at the physical desk, rather than online. This may be a reflection of our small campus at the University of Minnesota, Morris (UMM). It could also mean we're not getting our message out strongly enough. In the past we've relied on posters, social media posts, website news stories and library orientation to get the word out about our reference services. Even so, it can be easy for students to miss announcements or simply forget, especially when being bombarded with information. Based on the recent success of a library introductory video a colleague and I created using the Camtasia 9 software (we've had over 800 views since releasing it in the fall of 2017), I thought it might be a good idea to do something similar focusing solely on reference assistance.

Unless one is using a simple screencasting tool such as Screencast-O-Matic, creating videos often requires a time commitment, especially when learning new technology. 
Fortunately, Camtasia helps new users by being intuitive while also offering powerful editing features. The end results can be quite professional looking. "Other resources may be cheaper, but the quality of Camtasia videos are very strong; especially at this price point” (Kelley, 2014, p. 6).

Briggs Library certainly isn't alone in creating its own multimedia for outreach purposes. A 2011 survey of YouTube videos by subject heading showed that 55\% of the library videos created were of an introductory or general nature (Colburn \& Haines, 2012, p. 14). More recently, a poll conducted in early 2018 found that $94 \%$ of $18-24$ year-olds are users of YouTube (Smith \& Anderson, 2018). Knowing there was an audience I set about creating an Ask a Librarian video that would be informative and engaging.

My first step was writing a script. Unlike our earlier library introduction video, which was intended as a grand overview, this project would be much smaller in scope. Instead of multiple locations I planned to shoot most of the video with a web camera in a library multimedia space. It would also be considerably shorter. The main points to be covered were: Ask a Librarian — what is it, how can you contact a librarian, and what are the hours of service? A brief introduction and summary was also included, which I planned to videotape live. The rest would be handled as a voiceover with carefully chosen images as well as a screencast showing the location of key links on our website. Two PowerPoint slides would bookend the video.

With the script complete I turned to the creation of the video itself. Summer is the perfect time to work on projects at UMM since most of our students are away and the reference desk is on-call only. Even so, I was cognizant of the fact that since the campus technology help desk was moving to the library I would have a limited window of 
opportunity to use our small Camtasia studio before it was displaced. Before diving into recording, however, I spent a little time reviewing Camtasia 9 best practices through several Lynda.com tutorials. One of the most useful was titled Camtasia 9 for Windows Essential Training by Corbin Anderson. A subscription is necessary to access content on Lynda. Armed with my notes and script I began the recording process. Although my Ask a Librarian video was going to be very different from our earlier library introduction project I did want to include at least one element for continuity. In our first Camtasia video we had a library student employee dress up as our UMM mascot Pounce, a golden cougar. Like many full-bodied costumes it had a tendency to get hot and stuffy. With trepidation I approached the same work study student and inquired if he would consider donning the outfit again for a very short scene. To my relief he agreed. Using a video camera from our IT department I directed our furry actor in a brief scene. After a few minutes the location filming was complete.

One important thing to remember is that video files should not be renamed, however tempting this may be. Changing file names to correspond to their content can corrupt the metadata and can cause the files not to play properly in Camtasia. Avoiding this misstep I downloaded the video files to my workstation. Then I opened Camtasia and clicked on "New Project". Then I used the "Import" function to get my video files as well as other media into my Camtasia project.

Before recording my video introduction I checked the levels to make sure they were within an acceptable range. Although the computer was equipped with a built-in microphone I used an external Snowball microphone for better sound quality. It can also be helpful to have the script visible so you don't have to worry about forgetting any words. I taped mine to 
the computer so it was at eye level. It's also a good idea to limit your distractions so unwanted noise doesn't pollute an otherwise perfect take. Having a glass of water nearby can also be handy. Most importantly, if you're going on camera make sure you look presentable. How does the background look? Be aware of your mannerisms. I have a tendency to talk with my hands and shift my eyes from side to side. With a little effort I was able to curb these behaviors. So can you.

Working with Camtasia, as with any piece of new technology, has a learning curve. Although the software is user-friendly, if you have subscription access to the self-help website Lynda.com, I would recommend watching a Camtasia tutorial. I viewed "Camtasia for Windows: Essential Training" by Corbin Anderson. This introductory course introduced and explained the basic tools provided by the software, showcasing a project from start to finish. The video can be stopped and replayed as often as necessary. There are many more Camtasia tutorials available depending on your software version and skill level.

Once some background information has been gained, the next step is to orientate yourself to where important features are located within the Camtasia interface. The bottom of the screen comprises the timeline as well as assorted media tracks such as audio, video, images and closed captioning. Getting imported media into the timeline is as simple as dragging and dropping. Camtasia will automatically create a new track for you when new media is added to the timeline. Alternately, a new track can be created manually by clicking on the + button.

Ultimately, the hardest part of working with Camtasia isn't Camtasia at all; it's recording an error-free segment. I can be something of a perfectionist, but what I learned is that "good enough" is usually just fine. Try a few takes and use the best one. Librarian and 
videographer Anali Maughan Perry (2011) had this sage advice:

Accept that your videos won't be perfect, your acting won't win you awards, you'll have limits to your editing time and special effects, and the topics won't always be the most exciting. Once you've let go of these reservations, you can relax, have fun making the videos, and play to your strengths. Your videos will reflect your enjoyment of them, which encourages your audience to enjoy them, as well. (p. 283).

Where Camtasia really shines is in the editing process. Empty spots can be edited out by dragging the play marker so that the unwanted area is highlighted. Right-clicking will offer a variety of options, including "ripple delete", which will remove both the audio and video track content. Throat clearings can be hidden by dragging the audio level down. You can even split tracks, group tracks together and use the slider tool to zoom in or out. Just make sure to review your recordings thoroughly. The best time to change a mistake or unflattering moment is before a video gets shared.

Before long I was ready to do my voiceovers. These comprised the vast majority of the script. Although less pressure than the videotaping, voiceovers require that the media content (in my case, static images or screencasts) be synced with the script. I changed my recording settings to audio only and tackled the different voiceover segments. One challenge I encountered was matching my audio delivery with a PowerPoint text reveal. In most cases, however, syncing happens later in the editing process. During editing, I utilized the slider tool extensively in order to zoom in and make adjustments to different tracks in the timeline. Using Camtasia, it's easy to drag tracks so they align better with other content.

When I was done with the voiceovers as well as the vast majority of the editing, and had recorded the short video summary concluding the project I was ready to add some bells 
and whistles. Polishing and fine-tuning is one of the most enjoyable aspects of working in Camtasia. It feels a lot like playing. Don't be afraid to experiment. You can always undo or delete something if you don't like it. I added callouts (text boxes), transitions between segments as well as cursor effects for highlighting and visual effects for color/lighting adjustment. I also made sure my volume levels were consistent throughout the video. Camtasia also offers a small library of music files which can enhance your project.

Finally, I was ready to include closed captioning for accessibility. Extra care is required to ensure that the closed captioning text matches with the spoken content. Camtasia makes this relatively simple by allowing the replaying of a short segment over and over again until you have the text in place.

After several days of work (8 hours total) I was ready to render the finished project using the custom settings option, making sure that the 'Burned in Caption' option was checked. Then I saved it as a MPEG-4 file and uploaded it to our library YouTube channel. I've also shared it on our social media and digital signage system as well as embedded the video on several of our library webpages. The video has a total running time of 2:28, and although it's only half as long as our more comprehensive introductory library video, the length is still not ideal. In the future, I hope to follow the University of Arizona's advice and keep promotional videos to under 90 seconds (Perry, 2011, p. 282). Maybe next time I'll focus on our circulating board game collection.

Although it's too early to tell what the impact of our most recent video will be it was enjoyable to take a deeper dive into Camtasia and showcase our services in a fun and relaxed manner. Hopefully more people will learn what we have to offer and how we can be contacted for assistance. What about you? Are you ready for your close-up and trying your 
hand at creating a promotional library video?

\section{References}

Colburn, S., \& Haines, L. (2012). Measuring libraries' use of YouTube as a promotional tool: An exploratory study and proposed best practices. Journal of Web Librarianship, 6(1), 531. https://doi.org/10.1080/19322909.2012.641789

Kelley, J. (2014). Answering a question before they ask a question with Camtasia. Mississippi Libraries 77(4), 5-6.

Perry, A. M. (2011). Lights, camera, action!: How to produce a library minute. College \& Research Libraries News, 72(5), 278-283. https://doi.org/10.5860/crln.72.5.8563

Smith, S., \& Anderson, M. (2018, March 1). Social media use in 2018. Pew Research Center. Retrieved from http://www.pewinternet.org/2018/03/01/social-media-use-in-2018/ 